\title{
Project to sequence human genome moves on to the starting blocks
}

London. Almost exactly ten years after the idea was first suggested, funding agencies in the United States and Britain have given the green light to pilot projects designed - if successful - to lead to the first full-length sequence of the human genome.

Next Saturday (13 May), John Sulston, director of the Sanger Centre in Britain, and Bob Waterston, director of the Genome Sequencing Center at Washington University, St Louis, plan to outline a joint proposal for an international effort to achieve this objective to a meeting at Cold Spring Harbor, New York.

Research teams at various centres would be responsible for helping to sequence a set of cosmids covering each chromosome in turn. These sequences would then be combined, and the complete sequence data would eventually be placed in the public domain.

Although the specific strategy being suggested by Sulston and Waterston would, for technical reasons, result in a sequence that still contained some gaps, many feel that its cost - estimated at between $\$ 300$ and $\$ 500$ million - is sufficiently lower than earlier estimates to compensate for any omissions.

Sulston is also confident that a fully mapped sequence, even if only 99.9 per cent accurate, would still be invaluable to the whole research community. He says that the sequence could be established in as little as five years, and that the task is now timely and urgent. "Every year that goes by without embarking on this, we are wasting both money and time."

Agencies such as the National Institutes of Health (NIH) and the Department of

\section{Technicians die in Ariane $\mathbf{V}$ accident}

Paris. The European Space Agency (ESA) has set up an inquiry into the deaths last week of two technicians from France's national space agency (CNES) during pre-test verification checks on the cryogenic engines for the launcher Ariane V.

The technicians died by asphyxiation following the leak of liquid nitrogen. The inquiry is expected to provide details on the origins of the leak, which took place during inspection of the umbilical mast used to fuel the launcher on the launch-pad.

A spokesman for ESA said that the accident is unlikely to delay the first launch of Ariane V, still scheduled for the end of November, with the scientific mission Cluster as its pay-load.
Energy in the United States, and the Medical Research Centre (MRC) and the Wellcome Trust - the main supporter of the Sanger Centre - in Britain, appear to be in agreement.

The NIH, for example, has issued a request for applications for pilot large-scale sequencing projects, and is prepared to give applications for any such project "expedited treatment" in order for it to start by the end of the year. It has earmarked $\$ 20$ million to be distributed between such projects and work on advanced sequencing techniques.

Similarly the MRC has decided to make available some of the extra money it won from the government in this year's science budget for 'strategic' objectives.

Both Sulston and Waterston say they intend to apply for the funds being made available. Whether their specific proposals receive approval will depend on how they fare during the peer review process.

But, given the strong track record of both groups in sequencing the genome of the nematode worm Caenorhabditis elegans, there will be little surprise if their applications are successful.

Whatever the outcome, there is little doubt that the joint proposal has helped to crystallize a growing consensus that, after ten years of preliminary work, the time has arrived for a preliminary assault on the 3-billion bases of the complete human genome.

"There is a lot of interest in moving on to sequencing more quickly," says Elke Jordan of the NIH's National Center for Human Genome Research (NCHGR). "In the past few months, we have gone from a feeling that we were not quite ready to a feeling that 'yes, we should go'."

There is similar enthusiasm at the Wellcome Trust. "We have not yet agreed to fund the project; that will depend on the outcome of the normal peer review processes," says Michael Morgan, programme director at Wellcome. "But we would not be in this position [of accepting proposals] if we did not accept that it is a sensible thing to do."

Up to now, support for genome research by the NCGHR and other bodies has been distributed relatively widely. One priority, for examplc, has been novel sequencing technologies, based on the argument that large-scale sequencing should wait until the costs become significantly lower.

Some, indeed, continue to support this point of view, and advise caution before rushing ahead with the strategy that Sulston and Waterston are suggesting. Others, however, point out that there have been few

\section{IMAGE UNAVAILABLE FOR COPYRIGHT REASONS}

Worm's eye view: sequencing techniques for the nematode genome may now be applied to humans

major technical advances in sequencing in the past couple of years - and that waiting longer could delay the project unnecessarily.

In contrast, the proposal being put forward by Sulston and Waterston is built largely on techniques already in use in both laboratories to sequence the nematode as well as parts of the human genome.

The approach they suggest would be based on the so-called 'shotgun' sequencing of a minimal set of cosmids covering each human chromosome in turn. The resulting sequences will then be put together, with additional effort applied to 'finishing' the data where necessary.

Sulston says that, on the basis of their previous experience and simulations with available data, he and Waterston believe that the resulting sequences will contain no more than 3 gaps per cosmid - caused chiefly by long tandem repeats, inverted repeats and homopolymeric stretches. Nevertheless the sequence would still contain sufficient information to act as a fine-grain map containing, for example, the accurate location of the entire set of human genes.

"The general idea is to make a thorough attempt at maximal representation of the genome both at the clone level and at the sequencing level, and to tie the whole thing together by identifying the landmarks," says Sulston. "This will provide a means of organizing as much as possible of the information that is already being developed."

Sulston and Waterston claim that, if carried out on a large enough scale, the cost of sequencing could be reduced to about 10 cents a base (for comparison, the nematode 